\title{
Representações étnicas das identidades nacionais aroentina e brasileira em Carlos Gardel e Carmen Miranda
}

Alessander Kerber*

Resumo. Neste artigo, propõe-se uma análise das representações das identidades étnicas presentes nas músicas, na imagem e na performance de Carlos Gardel e Carmen Miranda, as quais foram relacionadas com as identidades nacionais da Argentina e do Brasil. Parte-se da hipótese de que esses dois artistas foram importantes nos processos de negociação e de construção das identidades nacionais argentina e brasileira, tendo em vista o fato de haverem se tornado os mais famosos intérpretes de seus países, divulgando representações consumidas por um amplo público, em uma época de emergência do nacionalismo no período de entre-guerras e de expansão dos meios de comunicação de massa. Nas músicas, nas imagens e nas performances desses dois artistas havia, também, representações de identidades étnicas, as quais eram afirmadas como legitimamente nacionais. Nesse sentido, enfocam-se identidades de caráter distinto - ligadas à etnicidade e à nação -, estabelecendo uma análise sobre a relação existente entre as mesmas nesse contexto.

Palavras-chave: Identidades Étnicas. Identidade Nacional. Carlos Gardel. Carmen Miranda.

* Doutor em História pela Universidade Federal do Rio Grande do Sul. Professor e pesquisador do Centro Universitário FEEVALE. E-mail: alekerber@feevale.br 
No presente artigo, proponho uma análise da relação entre identidades nacionais e étnicas a partir das representações presentes nas canções interpretadas por Carlos Gardel e Carmen Miranda no período entre-guerras. ${ }^{1}$ Houve, na Argentina e no Brasil, especialmente entre os anos 10 e 30 do século XX, um grande processo de renegociação e redefinição das representações das identidades nacionais. ${ }^{2}$ Nesse contexto, surgiram os primeiros artistas que se tornaram ídolos nacionais, tendo suas músicas difundidas nos vários espaços geográficos dos dois países, entre diversos grupos étnicos, especialmente através dos novos meios de comunicação que se massificavam naquela época: o rádio, o cinema e a indústria fonográfica. Alguns desses artistas, justamente por circularem entre meios culturais distintos, participaram como mediadores do processo de construção de uma nova síntese identitária nacional.

Considero as trajetórias musicais de Carlos Gardel e de Carmen Miranda como vias privilegiadas para a análise das identidades nacionais argentina e brasileira. Há uma série de elementos que justificam essa escolha. Eles não apenas foram os cantores populares de maior sucesso em seus respectivos países, como também alcançaram grande sucesso internacional, construindo um imaginário acerca da Argentina e do Brasil. Como grandes ídolos populares, divulgavam idéias, símbolos e estereótipos que eram consumidos por grande parte da população.

Os estrondosos sucessos de Gardel e Carmen mostram a dimensão da importância desses artistas na construção da identidade de seu público. Apenas para citar um exemplo, a música Taí, marcha de Joubert de Carvalho, lançada por Carmen Miranda em 1930, vendeu mais de 35 mil discos, constituindo-se a maior vendagem discográfica da história do Brasil até aquele momento. $\mathrm{Na}$ mesma época, uma música de Carnaval de grande aceitação vendia em torno de 5 mil cópias. Por isso, o jornalista Teófilo de Barros, em artigo publicado na Revista Carioca, em 15 de maio de 1937, falava: 
Se Carmen gravar uma música qualquer horrorosa, essa música se vende aos milheiros, é tocada, cantada, assobiada até azedar e encher de dinheiro as editoras. O compositor pode ser até qualquer um. Não tem importância. Ficará importante do dia para a noite. (BARROS apud CARDOSO JUNIOR, 1978, p. 383)

Durante toda a década de 1930, Carmen foi a maior vendedora de discos do Brasil, superando de longe os outros cantores considerados de sucesso. Além disso, mais recentemente, focalizando a carreira de Carmen a partir da revista O Cruzeiro, Garcia (1999) constata que a cantora já era associada à identidade nacional durante os anos 1930, sendo chamada de "cantora do it verde-amarelo". Nesse sentido, várias reportagens a vinculavam ao caráter nacional na época.

No caso de Gardel, Peluso e Visconti, em seu livro sobre a repercussão do cantor na imprensa mundial, indicam, também, tal associação. Por exemplo, o Anuario Teatral Argentino de 1924 anunciava: "Es el duo de cantos nacionales más popular de la República Argentina. Ellos cultivan con fidelidad e inimitable gusto, todo el cancionero típico porteño y folklorista argentino" (apud PELUSO; VISCONTI, 1998, p. 39). ${ }^{3}$

Tal qual o estrondoso sucesso de Carmen com a música Taí, Gardel teve uma "explosão" com a canção Mi noche triste, tango de Samuel Castriota e Pascual Contursi, gravado em 1917. Essa canção, além do grande sucesso, teve tanta importância que é considerada o marco de uma nova fase na história do tango.

Merece menção o fato de que Carmen Miranda era, essencialmente, uma intérprete, enquanto Gardel era compositor e intérprete. Isso, porém, não se apresenta como um empecilho para este trabalho. Comumente, a propriedade de uma música é dada ao seu compositor. Nesse trabalho, porém, o corpus documental refere-se aos intérpretes. Nesse sentido, uma indagação poderia recair sobre a validade da análise de músicas compostas por uma grande variedade de 
compositores. Dart, no livro Interpretação da música, analisa as diversas formas de expressão artística, afirmando que elas "podem ser divididas em dois grupos: as criadas em definitivo (como pintura, escultura, arquitetura) e as recriadas (música, teatro, dança). Assim, as artes deste último grupo dependem de um segundo artista para serem representadas. Enquanto o compositor é aquele que tem a idéia inicial, o intérprete é quem concretiza a obra em nível sonoro (1990, p. 4). Assim, cabe ao intérprete uma parcela importante da produção da música propriamente dita.

Outro elemento que justifica a opção, nesta pesquisa, pelas canções interpretadas (e não compostas) por Carmen é o fato de que, exatamente por ser a intérprete mais famosa e que mais vendia discos no Brasil, era ela quem escolhia as canções que gravaria, dentre uma grande quantidade enviada pelos principais compositores da época. ${ }^{4}$ A escolha e a interpretação conferem uma unidade à obra de Carmen, que buscava sua própria identidade musical dentre a diversidade de canções que lhe eram apresentadas.

Dessa forma, as fontes utilizadas para esta pesquisa são as canções gravadas por Gardel e Carmen, que são em número de 930 e 281, respectivamente. Como fontes secundárias, analisei também os filmes que contaram com a participação de ambos, os quais dão importantes subsídios sobre a performance desses artistas. ${ }^{5}$

Quanto à cronologia deste trabalho, tem-se que levar em consideração que a trajetória artística solo de Gardel inicia-se aproximadamente uma década antes da de Carmen. ${ }^{6}$ Também é importante assinalar que a trajetória de Carmen analisada estendese até meia década após a morte de Gardel. Essa diferença de datas não impossibilita, porém, a comparação entre esses casos, levando-se em consideração a perspectiva da história comparada em sua exigência de similitudes profundas entre as sociedades enfocadas. Nesse sentido, Bloch (1963, p. 19) define como necessário, na escolha de sociedades para comparação, que estas sejam "ao mesmo tempo vizinhas e contemporâneas, constantemente 
influenciadas umas pelas outras, sujeitas em seu desenvolvimento, em razão da sua proximidade e da sua sincronização, à ação das mesmas grandes causas e remontando, ao menos parcialmente, a uma origem comum".

Dessa forma, a história comparada consiste em buscar as semelhanças e as diferenças apresentadas por duas séries de natureza análoga, tomadas de meios sociais distintos. Essa diferenciação cronológica justifica-se tanto pelas trajetórias artísticas de Gardel e Carmen quanto pelo contexto histórico específico em que se inserem os dois artistas, tendo em vista que houve, na Argentina, um desenvolvimento e uma massificação dos meios de comunicação de massas um pouco anterior ao caso brasileiro. Houve ainda uma diferença cronológica entre Argentina e Brasil em relação ao processo de emergência política de segmentos sociais excluídos. $\mathrm{Na}$ Argentina e no Brasil, as elites tradicionais foram obrigadas a incluírem politicamente os segmentos sociais excluídos a partir da vitória eleitoral de Hipólito Yrigoyen, em 1916, e da Revolução de 1930, respectivamente. Essa transformação no Estado tem influência sobre as lutas simbólicas no processo de definição das representações das identidades nacionais. Além disso, essa demarcação cronológica, na qual se inserem as trajetórias artísticas analisadas de Gardel e Carmen, encontra-se dentro do período entreguerras (1918-1939). Hobsbawm (1990, p. 159) situa o período de apogeu dos nacionalismos no mundo entre 1918 e 1950, ou seja, justamente entre o final da Primeira Guerra Mundial e o final da Segunda, período dentro do qual está compreendido este trabalho.

\section{Representações e identidades nacionais}

Para este estudo, tomei por base as discussões sobre representações e identidades nacionais, partindo principalmente das considerações de Chartier (1990, 2002), que afirma que, na compreensão 
do real, há um processo de significação e de associação com símbolos já existentes no imaginário do grupo ao qual pertence o indivíduo que apreende uma dada realidade. Uma realidade, assim, nunca é apreendida de forma pura; sempre é apropriada e simbolizada pelos grupos que dela se aproximam. E é nessa atribuição de sentido que percebo que as representações não são "ingênuas". Apesar de proporem-se a uma aproximação com a realidade, essas representações sempre são influenciadas pelos interesses dos grupos que as produzem. Como afirma Chartier (1990, p. 17),

as representações do mundo social assim construídas, embora aspirem à universalidade de um diagnóstico fundado na razão, são sempre determinadas pelos interesses de grupo que as forjam. Daí, para cada caso, o necessário relacionamento dos discursos proferidos com a posição de quem o utiliza.

As percepções do social não são de forma alguma discursos neutros: produzem estratégias e práticas (sociais, escolares, políticas) que tendem a impor uma autoridade à custa de outros, por elas menosprezados, a legitimar um projeto reformador ou a justificar, para os próprios indivíduos, as suas escolhas e condutas. Por isso esta investigação sobre as representações supõe-nas como estando sempre colocadas num campo de concorrências e de competições cujos desafios se enunciam em termos de poder e de dominação. As lutas de representações têm tanta importância como as lutas econômicas para compreender os mecanismos pelos quais um grupo impõe, ou tenta impor, a sua concepção do mundo social, os valores que são os seus e o seu domínio.

É possível identificar os elementos que compõem a representação. Há um significante, algo real, material, e um significado, algo dado a esse real pelos que o interpretam, a partir dos desejos e das necessidades conscientes e inconscientes destes. Pesavento (1994, p. 165), seguindo o pensamento de Chartier, define esses elementos, afirmando que:

Anos 90, Porto Alegre, v. 15, n. 27, p. 325-358, jul. 2008 


\section{Alessander Kerber}

todas as sociedades, ao longo de sua história, elaboram para si um sistema de idéias e imagens de representação coletiva através das quais elas estabelecem sua identidade, hierarquizam valores, pautam condutas e estabelecem formas de coesão social. Parte-se do pressuposto, contudo, de que o imaginário social, assim constituído, não é um reflexo do real, mas uma sua representação. É certo que ele contém um fio terra, que o liga ao real, às condições concretas da existência e que lhe dá credibilidade. Mas o imaginário contém, também, um componente de intencionalidade, de manipulação do que se poderia chamar "ỉlusão do espírito", ou ideologia. Da mesma forma, o imaginário comporta uma dimensão de sonho, de desejo, de vir-a-ser, de inconsciente coletivo que todas as sociedades elaboram.

Uma identidade expressa-se justamente por meio de representações que definem a idéia e o sentimento de pertencer a um grupo. Assim, ela é, ao mesmo tempo, sentimento e idéia, é sentida e pensada como formulação de uma imagem de si mesmo, ou seja, como auto-representação. Essa consciência de si a partir de representações impõe limites às práticas sociais dos indivíduos. Esses limites estão em torno das fronteiras entre um grupo e outro. Uma identidade forma-se, assim, além da percepção das representações comuns, entre o grupo, por meio da percepção da diferença, em relação ao outro grupo, ou seja, em uma relação de alteridade.

Ao analisar a construção de identidades, Chartier aponta para as perspectivas que a história cultural trouxe a essa questão, diferenciadas de duas visões existentes anteriormente: uma que via as identidades como resultado de imposições de representações e resistências contra estas, outra que as via como exibição de uma unidade construída a partir de um grupo. O autor afirma que:

trabalhando sobre as lutas de representações, cujo objetivo é a ordenação da própria estrutura social, a história cultural afasta-se sem dúvida de uma dependência demasiado estrita 
em relação a uma história social fadada apenas ao estudo das lutas econômicas, mas também faz retorno útil sobre o social, já que dedica atenção às estratégias simbólicas que determinam posições e relações e que constroem, para cada classe, grupo ou meio, um "ser-percebido" constitutivo de sua identidade. (CHARTIER, 2002, p. 73)

Uma identidade nacional se forma por meio de um sentimento e uma idéia de pertencimento a uma nação. Utilizo o conceito de Anderson, que assinala que a nação não existe em outra instância senão no imaginário de uma comunidade. Para o autor, a nação é

uma comunidade política imaginada - e imaginada como implicitamente limitada e soberana. Ela é imaginada porque nem mesmo os membros das menores nações jamais conhecerão a maioria dos seus compatriotas, nem os encontrarão, nem sequer ouvirão falar deles, embora na mente de cada um esteja viva a imagem de sua comunhão [...] é imaginada como limitada, porque até mesmo a maior delas, que abarca talvez um bilhão de seres humanos, possui fronteiras finitas, ainda que elásticas, para além das quais encontram-se as outras nações. Nenhuma nação se imagina coextensiva com a humanidade. [...] É imaginada como soberana, porque o conceito nasceu numa época em que o Iluminismo e a Revolução estavam destruindo a legitimidade do reino dinástico hierárquico divinamente instituído. [...] é imaginada como comunidade porque, sem considerar a desigualdade e exploração que atualmente prevalecem em todas elas, a nação é sempre concebida como um companheirismo profundo e horizontal. Em última análise, essa fraternidade é que torna possível, no correr dos últimos dois séculos, que tantos milhões de pessoas, não só se matem, mas morram voluntariamente por imaginações tão limitadas. (ANDERSON, 1989, p. 14-16)

Essa comunidade imaginada se identifica a partir de uma série de símbolos. Segundo Thiesse (2001/2002, p. 8-9), existe um check 


\section{Alessander Kerber}

list, um código de símbolos internacionais que define o que todas as nações devem ter: uma história estabelecendo a continuidade da nação; uma série de heróis, modelos dos valores nacionais; uma língua; monumentos culturais; um folclore; lugares memoráveis e uma paisagem típica; uma mentalidade particular; identificações pitorescas - costumes, especialidades culinárias ou animal emblemático. Esses símbolos não são apenas uma superficial lista de adornos, mas algo essencial para a auto-representação das pessoas que se identificam com a nação.

O contexto em estudo é diferente daquele no qual os primeiros teóricos europeus começaram a discutir a nação. É a Argentina e o Brasil dos anos 1910 aos 1930, que possuem outras formas, mais eficientes, de difusão de representações do que as do século passado. Refiro-me especialmente aos meios de comunicação de massa. Como afirma Backzo (1985, p. 313),

os meios de comunicação de massa garantem a um único emissor a possibilidade de atingir simultaneamente uma audiência enorme, numa escala até então desconhecida. Por outro lado, os novos circuitos e meios técnicos amplificam extraordinariamente as funções performativas dos discursos difundidos e, nomeadamente, dos imaginários sociais que eles veiculam. Tal facto não se deve apenas à natureza audiovisual das novas técnicas, mas também, e sobretudo, à formação daquilo a que se dá o nome, à falta de melhor, de "cultura de massa". Tecem-se ao nível desta última relações extremamente complexas entre informação e imaginação.

Os meios de comunicação têm uma grande importância no sentido de tornar as representações sobre a nação não mais restritas a um público letrado, mas difundidas massivamente. As lutas de representações em torno da construção da identidade nacional da Argentina e do Brasil tiveram os meios de comunicação de massa, emergentes nesses dois países exatamente nesse período, como espaço privilegiado.

Anos 90, Porto Alegre, v. 15, n. 27, p. 325-358, jul. 2008 
No Brasil, as primeiras experiências com rádio datam de 1922, enquanto a sua massificação inicia-se na década de 1930, justamente no período varguista. Já na Argentina, essa massificação ocorreu anteriormente e está associada ao poder de consumo da sociedade argentina. Conforme Haussen (1997, p. 25),

na Argentina [...] a indústria de equipamentos radiofônicos desenvolveu-se mais velozmente que a brasileira, bem como o contexto sócio-econômico e cultural era diverso. [...] No final da década de 20, havia no Brasil 19 emissoras em funcionamento enquanto que na Argentina, um país com um número bem menor de habitantes e com uma extensão territorial inferior à brasileira, 36 emissoras já estavam instaladas. E não era só no número que se estabelecia a diferença: esta ocorria também na publicidade, na tecnologia e no conteúdo.

Enquanto no Brasil a programação de cunho educativo e cultural permaneceu por mais tempo, com as emissoras sendo constituídas como radioclubes ou radiossociedades, na Argentina a influência da publicidade começou bem mais cedo. [...] já em dezembro de 1922 surgia a primeira emissora comercial, a "LOX Rádio Cultura", de Buenos Aires.

Segundo Collier, a indústria fonográfica havia se desenvolvido na Argentina desde a década de 1910 e o rádio, desde 1920.

Las emisoras de radio - las broadcastings, como las llamaban entonces los argentinos - proliferaban en Buenos Aires y las otras ciudades principales: se instalaron más de cincuenta entre 1920 y 1928. Así los horizontes del entretenimiento popular, ya ampliados por el fonógrafo, se ampliaron aun más, en un último hito antes de la era de la televisión. La Argentina estaba convirtiendo en una "sociedad de masas" con sus correspondientes entretenimientos masivos. Era inevitable que el dúo de cantores más famoso del país saliera al aire tarde o temprano. (COLLIER, 1988, p. 101) 
Enquanto a década de 1920 já assistia, na Argentina, à aparição do rádio comercial, no Brasil, a regulamentação para propaganda veio apenas na época de Vargas, em 1932. Foram justamente os anos 1930 que assistiram, no Brasil, à emergência desse novo meio de comunicação de massas. Em 1937, havia 63 estações de rádio e 357.921 aparelhos no Brasil, sendo que nos primeiros anos do Estado Novo esse número duplicou (CAPELATO, 1998, p. 77).

Ao lado do rádio, outra nova tecnologia, o gramofone, auxiliou na difusão e na massificação da música. Gardel e Carmen também foram os primeiros maiores vendedores de discos da Argentina e do Brasil. Da mesma forma que os aparelhos de rádio, os gramofones chegaram inicialmente às casas das elites e, no decorrer da década de 1930, passaram por um processo de relativa massificação, apesar de nunca terem chegado aos níveis de vendas dos aparelhos de rádio.

\section{Identidades étnicas na Argentina e no Brasil}

Entendo as identidades étnicas como uma construção constante, que se relaciona com as necessidades contemporâneas de cada grupo e não como algo dado naturalmente. Retomo, dessa forma, a idéia de Barth (1998, p. 188), para quem

as distinções étnicas não dependem de uma ausência de interação social e aceitação, mas são, muito ao contrário, freqüentemente as próprias fundações sobre as quais são levantados os sistemas sociais englobantes. A interação em um sistema social como este não leva a seu desaparecimento por mudança e aculturação; as diferenças culturais podem permanecer apesar do contato interétnico e da interdependência dos grupos.

As identidades nacionais, ao serem construídas, tiveram de ser relacionadas a outras identidades já existentes anteriormente. Dentre as populações argentina e brasileira havia identidades étnicas 
com as quais as identidades nacionais precisariam dialogar, no sentido de construir uma representação homogênea da população. A emergência social e política de segmentos populares, ocorrida especialmente no período demarcado neste estudo, foi um dos elementos que geraram a necessidade de renegociação da identidade nacional em ambos os países. Porém, essa emergência, no Brasil, implicou lutas de representação com caráter étnico muito maiores que na Argentina. No Brasil, acabou tornando-se dominante, nesse processo, a versão de um país mestiço, mesmo considerando a existência de outras versões em disputa no espaço das lutas de representações, enquanto a idéia de uma nação branca prevaleceu na Argentina.

Fausto e Devoto (2004, p. 221) analisaram essa questão, afirmando que:

No interior deste quadro, a diferença no trato do tema, entre brasileiros e argentinos, diz respeito à ênfase das preocupações. Em um país como a Argentina, em que a escravidão praticamente desaparecera desde meados do século XIX, sem deixar traços visíveis, as cogitações sobre o "branqueamento" da raça não estiveram ligadas à questão social do negro, como ocorreu no Brasil. Estudos pretensamente científicos sobre a inferioridade racial do negro e críticas a estes estudos, como é fácil imaginar, praticamente inexistiram na Argentina; mas constituíram, ao contrário, uma das obsessões do pensamento social brasileiro até o surgimento da obra de Gilberto Freyre, a partir dos anos 30 do século XX. Ressalvem-se figuras como Alberto Torres e Manoel Bonfim, que valorizaram o negro e o processo de miscigenação, e desvalorizaram, ao mesmo tempo, o papel do imigrante na vida social brasileira.

Ao analisar a formação étnica argentina e suas conseqüências sobre o tango, Martinez, Etchegaray e Molinari identificam dois grandes processos de choque cultural. O primeiro, seria o transcorrido 


\section{Alessander Kerber}

durante o período colonial, no violento encontro entre os espanhóis e as populações nativas americanas. Essa violência, que se expressava sob diversas maneiras, desde a imposição de formas de trabalho, passando por estupros e até assassinato, esteve presente de forma marcante quando da formação e da emergência da cidade de Buenos Aires, já no século XVI, como ponto privilegiado de comércio que fazia escoar imensas riquezas em prata de Potosi para a Europa. Tais autores assinalam que, desde o início, Buenos Aires teve formação mestiça, e a própria mestiçagem foi a responsável pela criação do gaucho, que, posteriormente, a partir de Martín Fierro, tornou-se símbolo nacional argentino. O segundo grande choque ocorreu quando do intenso processo de imigração européia, entre o final do século XIX e início do XX (MARTINEZ; ETCHEGARAY; MOLINARI, 2000, p. 150).

Esse segundo grande choque teve, na cidade de Buenos Aires, espaço privilegiado, especialmente, nas orillas. Como afirmam Martinez, Etchegaray e Molinari, nessas orillas, dois foram os locais privilegiados: os conventillos e os prostíbulos.

Esta caótica "invasión" de "gringos" comienza a poblar las ciudades que no estaban preparadas para recibir esta marea humana. Aparece entonces el conventillo como "solución" y se adecuan viejas casas del casco histórico, abandonadas por la epidemia de fiebre amarilla de 1871 y se construyen otras viviendas al efecto. En estas pocilgas conviven los recién llegados, italianos, españoles, franceses, polacos, rusos, con los gauchos expulsados por el alambrado y el nuevo orden económico y los pocos negros sobrevivientes de tantas penurias.

Es entonces, que en los conventillos, en las orillas de la ciudad se produce el otro encuentro de culturas. Mientras que el primero fue entre los conquistadores españoles y los indígenas, este segundo encuentro se da también entre europeos y nativos, pelo ahora ambos pertenecientes a la misma escala social. Los marginados de afuera se encuentran con los 
marginados de adentro, el conventillo será el lugar emblemático de este encuentro. [...] el prostíbulo como el otro lugar de encuentro que, junto al conventillo, van a definir una nueva cultura urbana de la cual el tango es el principal emergente. (MARTINEZ; ETCHEGARAY; MOLINARIA, 2000, p. 162-163)

Frise-se que tanto o tango quanto o próprio Gardel têm sua origem relacionada exatamente a esses espaços, algo que os legitima como ligados, também, ao mito fundador da identidade nacional argentina. $\mathrm{Na}$ Argentina, esses imigrantes de diversas etnias construíram, em geral, identidades associadas à exclusão, no decorrer do século XIX. Eram, em sua maioria, pessoas sem instrução profissional, fator que influenciava em sua colocação em estratos inferiores na ordem econômica. Daí que, conforme Carretero (1999, p. 36),

Con la consecuencia de la peste de 1871, la mayoría de la población de San Telmo y Monserrat [barrios periféricos de Buenos Aires] y parte de otros barrios afectados, los abandono, quedando muchas casas vacías. Los pudientes se transladaran al norte. Todas esas casas se invirtieron en lugares preferidos para vivir los italianos (tanos), vascos (tarugos), árabes (turcos), españoles (gallegos) y las otras nacionalidades, por la baratura de los alquileres.

Ao analisar alguns dos principais teóricos que pensaram sobre a identidade nacional argentina no século XIX, Devoto afirma que o processo imigratório ocorrido nesse país não foi apenas causa para transformações na identidade nacional, mas também conseqüência de um desejo de parte da intelectualidade que pensava soluções para o "atraso". Nesse sentido, Devoto refere-se às obras de Juan Bautista Alberdi, Sarmiento e Bartolomé Mitre. Segundo o autor (DEVOTO, 1999, p. 35-36), para o primeiro desses três pensadores, a imigração teve um papel muito mais amplo do que apenas fornecer mão-de-obra, substituindo uma população arcaica por uma nova, 
proveniente da Europa mais desenvolvida (do norte); o segundo, pensou a imigração como sendo a responsável pela vitória da cidade sobre o campo; e o terceiro, concebeu um futuro de grandeza, caso houvesse a integração dos novos imigrantes ao curso de evolução de uma identidade histórico-cultural preexistente.

Contudo, a nação argentina, bem como qualquer outra, não poderia igualar a identidade à alteridade, definindo-se a partir do elemento estrangeiro europeu. Essa estratégia funciona, como mencionei, para definir a alteridade em relação a outros países da América Latina. Porém, a Argentina também precisava marcar sua diferença em relação às identidades nacionais européias e, nesse sentido, era necessário "argentinizar" esses imigrantes, ou seja, tornar esses europeus argentinos, o que implicava fazer com que eles compartilhassem de uma identidade nacional. Obviamente, essa cultura argentina teria que ser buscada em algo anterior à imigração. Mas, o que poderia sintetizá-la?

Conforme Prieto (1988), na época da Primeira Guerra, os nacionalistas argentinos já haviam encontrado no homem gaucho um símbolo que representasse a herança cultural da nação sob a "ameaça" da imigração. Tal qual no caso brasileiro, boa parte dos intelectuais argentinos do final do século XIX imaginaram que a chegada de imigrantes brancos europeus melhoraria a raça e o trabalho da população criolla. Archetti (2003) afirma que o discurso nacionalista reviveu os temas "bárbaros" que tinham sido condenados a desaparecer por meio da imigração, da hibridação e da modernização. Essa reinvenção da tradição tornou-se possível em virtude do lugar privilegiado que a literatura gauchesca ocupava no consumo literário popular urbano e rural desde os anos 1880. Assim, a história do gaucho que lutava contra a injustiça do Estado a fim de manter sua liberdade foi transformada em modelo para uma "literatura nacional". A imagem do gaucho foi um elemento fundamental na construção da identidade nacional argentina. $\mathrm{O}$ sucesso de Martín Fierro e do circo criollo, a partir do final do século XIX, são provas disso. 
Ao analisar a origem do tango, Martinez, Etchegaray e Molinari (op. cit., p. 60-64) identificaram sua formação a partir de um processo de miscigenação. A música popular existente na Argentina na primeira metade do século XIX foi "protagonizada" pelos negros em seus bailes e difundida entre outros meios étnicos. Assim, a herança africana teria sido uma das bases de origem do tango, mesmo com a saída da maioria dos negros da região durante o século XIX. Por outro lado, nos salões do centro da cidade, dançavam-se músicas européias, como valsa, polca, minueto e gavota. Nas primeiras décadas do século XX, especialmente a partir de seu sucesso internacional, este estilo musical mestiço tornou-se mais aceito pelas elites argentinas e representação nacional.

As nações argentina e brasileira têm, dentre as "identificações pitorescas" do check list proposto por Thiesse, estilos musicais como representações. Importante salientar, para o enfoque desta pesquisa, que ambos os estilos apresentam, - tal como os artistas aqui analisados - além de relações com as identidades nacionais, também relações com as identidades étnicas. Conforme Napolitano (2006, p. 2.908),

Há um consenso entre os estudiosos do gênero que quero sublinhar: o samba não pode ser dissociado das práticas e hábitos musicais dos grupos pobres, negros e mestiços do Rio de Janeiro e, ao se transformar em forma de canção, conheceu um processo de apropriação e nacionalização, via rádio, ao longo dos anos 1930. Este processo não foi linear nem isento de conflitos entre os diversos atores (jornalistas, cronistas, burocratas da cultura, músicos).

O autor, ao mencionar "pobres, negros e mestiços", aponta para a relação existente entre o estilo musical, as identidades étnicas e a condição econômica. O caso brasileiro destaca-se, mais do que o argentino, por essa associação entre dois tipos de identidade. Diversos autores associam a transformação nas concepções que se referem 
à identidade étnica da nação às novas percepções e políticas ligadas ao trabalho nos anos 1930. ' Capelato, ao analisar a relação entre identidades nacional e étnica, enfocando a educação, afirma que:

As teses baseadas nas ciências biológicas e na sociologia evolucionista orgânica que justificara o racismo e a necessidade de branqueamento na sociedade até o final dos anos 20 foram sendo, paulatinamente, substituídas por outras perspectivas que acabaram por valorizar a miscigenação. A necessidade de aproveitamento do trabalhador nacional explica, em parte, essa mudança. Mas a justificativa dessa nova postura aparecia relacionada à preocupação com a unidade étnica do país, elemento importante na construção da consciência nacional. O negro, o índio e o mestiço, antes considerados excluídos da civilização (porque estavam à margem do mercado de trabalho) e responsabilizados pelo atraso do país, passaram a ser enaltecidos como elementos de progresso. (CAPELATO, 1998, p. 229)

É nesse contexto que, como aponta Vianna (1995), emergem versões acerca da identidade nacional brasileira que exaltam a miscigenação, bem como signos associados a ela, como o samba, como representações nacionais.

\section{Carlos Gardel na Argentina}

Ao comparar a identidade nacional argentina com a brasileira, Rojo (1996) sintetiza-as nas imagens do estrangeiro e do mestiço. A Argentina teria construído sua identidade nacional a partir da idéia de ser composta por brancos vindos da Europa, ou seja, uma nação de estrangeiros, enquanto o Brasil teria construído a sua a partir da idéia de mestiçagem. Analisando essas imagens, Rojo recorre a uma ironia de Carlos Fuentes, que dizia que os mexicanos descendem dos astecas, os guatemaltecos descendem dos maias, 
os peruanos descendem dos incas e os argentinos descendem dos barcos. Também recorre à idéia de Jorge Luis Borges, que disse que os argentinos são uns italianos que falam espanhol, tomam-se por ingleses e sonham com a França. Como afirma Rojo (ibid., p. 123), "Los argentinos (y los uruguayos, esos rioplatenses de la orilla de frente) se identificaron, pues, con extranjero y como extranjeros fueran considerados por sus vecinos".

Isso me parece, inicialmente, uma grande contradição: pensar a identidade como alteridade, ou seja, o argentino é o estrangeiro. Porém, essa contradição pode ter uma explicação muito plausível. $\mathrm{Na}$ construção de sua identidade, a Argentina pensou sua alteridade mais em relação à América Latina do que às outras partes do mundo. E, nesse sentido, em relação à América Latina, a Argentina vem a ser uma nação de europeus, a grande nação branca desta parte da América. Contudo, essa definição da Argentina como uma nação branca oculta um processo de miscigenação que também ocorreu nesse país.

Gardel, em sua trajetória artística, utilizou-se da imagem do gaucho, tanto em sua carreira na Argentina quanto no exterior, bem como de diversas outras representações associadas à identidade étnica. Dentre os codinomes associados a Gardel - Carlitos, Gardelito, El Maestro, El Morocho, El Morocho del Abasto, El Zorzal, El Zorzal Criollo, El Bronce que sonrie, El Aficionado, El que canta cada día mejor, El Francesito, El Patrón de Buenos Aires, El Hombre, La Voz Inolvidable, El Cantor de Buenos Aires -, alguns têm caráter claramente étnico.

A figura do morocho, tal qual a do moreno, no Brasil, pode ser vinculada à miscigenação, bem como aos europeus latinos que compunham a nação argentina. É uma expressão que poderia, dada a sua amplitude e, mesmo, ambigüidade, ser utilizada como representação nacional. Por outro lado, o codinome "Francesito", dado seu local de nascimento, ${ }^{8}$ define este representante da identidade nacional argentina como francês, algo só possível, como mencionado, 


\section{Alessander Kerber}

em um país como a Argentina, em que a identidade foi definida a partir do estrangeiro. Otero (1999, p. 145), ao analisar a imigração francesa para a Argentina e sua integração nessa sociedade, afirma que:

Os franceses caracterizaram-se por ser um dos grupos de mais rápida integração na sociedade receptora [...] Se considerarmos, por exemplo, o casamento misto como um dos indicadores claros de integração estrutural na sociedade nativa, obteremos a imagem de que o processo teria sido rápido e bem sucedido.

Nesse sentido, Gardel pode ser pensado, além de estrangeiro, como pertencente ao grupo de estrangeiros que mais teve facilidade de miscigenar-se e integrar-se na identidade nacional argentina.

As letras do tango, muito freqüentemente, destacam o sofrimento envolvido neste processo de imigração. Varela (1998, p. 64), em Tangos que cantó Gardel, afirma: "La inmigración, el desarraigo (y muchos años más tarde el exilio y el destierro) son traumas recurrentes del inconsciente colectivo de los argentinos".

É possível supor que esse sofrimento tenha sido elemento presente na construção de uma síntese identitária argentina. Conforme Aguinis (2002, p. 63), o sofrimento é algo que "une" os imigrantes, constituindo esse companheirismo profundo e horizontal do qual se alimenta a identidade nacional. Como afirma,

Assim, ficaram lado a lado os descendentes do gaúcho e os recém-chegados da Europa. Uns desconfiados dos outros. Com desdém, piadas ou silêncios eles disfarçavam o medo. Os dois grupos carregavam frustrações e saudades. O imigrante desenraizado e o descendente do gaúcho morto não sabiam que a dor os unia.

O sofrimento do imigrante é tema recorrente nas canções interpretadas por Gardel, como em Galleguita, tango de Alfredo Navarrine e Horacio Pettrossi, gravado em 1925:

Anos 90, Porto Alegre, v. 15, n. 27, p. 325-358, jul. 2008 
Galleguita la divina

La que a la playa argentina

Llegó una tarde de abril

Sin más prendas ni tesoros

Que sus bellos ojos moros

Y su cuerpito gentil

Siendo buena eras honrada

Pero no valió de nada

Que otras cayeron igual

Eras linda, galleguita

Y tras la primera cita

Fuiste a parar al Pigalle

Sola y en tierras extrañas

Tu caída fue tan breve

Que como bola de nieve

Tu virtud se disipó

Tu obsesión era la idea

De juntar mucha platita

Para tu pobre viejita

Que allá en la aldea quedo [...]

Nessa canção, Gardel remete ao drama da "galleguita", ou seja, a representante da imigração espanhola. No sofrimento ligado à condição econômica também pode ser encontrado um elemento em comum entre os imigrantes e as populações que já estavam na Argentina antes da sua chegada, especialmente o gaucho. De origem pobre, tendo passado por dificuldades materiais e, freqüentemente, filho de pai desconhecido (como também era Gardel) ou morto, o gaucho traz consigo, também, essa identificação. No cinema, Gardel utilizou muito essa imagem. No filme El día que me quieras, de 1935, a imagem adotada pelo artista parece misturar elementos da indumentária gaucha com outros, que remetem aos descendentes de imigrantes portenhos. Por exemplo, seu lenço, colocado no pescoço de forma distinta dos outros gauchos que aparecem no filme, parece um cachecol, que remete à indumentária trazida pelos imigrantes. 
Sendo ele mesmo o compositor de boa parte das canções que interpretava, percebe-se um esforço de Gardel em construir essa identidade com segmentos populares, sejam eles da cidade, sejam do interior. Nesse processo, a questão étnica despontava como significativa. No espaço urbano, conviviam várias etnias, que tiveram participação em uma série de manifestações culturais que passaram a ser definidas como representações nacionais, principalmente no tango. Existem vários estudos recentes sobre a participação de grupos étnicos imigrantes na formação do tango. Por exemplo, em seu estudo sobre a influência da imigração italiana sobre o tango, Ostuni afirma que o tango-canção - que, como já mencionado, teve como marco inicial Mi noche triste, na voz de Gardel recebeu, em sua gênese, forte influência da cultura trazida pelo imigrante italiano.

El tango-canción, es cierto, no tiene las apetencias provocativas de la milonga o del tango orillero, pero en cambio atesora la certidumbre de una prole transida de seres con sus miserias y sus grandezas, con innumerables rostros de dolor y de alegría: habitantes de los paisajes del fracaso y sus letras junto con esa mezcla milagrosa de sabihondos, suicidas y derrotados en la utopía de querer vencer al tiempo. El tangocanción, más allá de ser música, danza o versos para el canto, es un modo de sentir la vida, de expresar los sueños y de interpretar el drama de la existencia humana.

Mucho han contribuido los inmigrantes italianos y sus descendientes a la grandeza universal del tango. Muchas de las más bellas melodías reconocen autores de ascendencia peninsular. (OSTUNI, 2005, p. 35).

Nesse sentido, o autor parece ligar a identidade nacional argentina, representada no tango, à etnicidade dos imigrantes italianos. O tango teria sido originado, conforme ele, pelo amálgama existente em Buenos Aires entre a cultura trazida pelo criollo, a trazida pelos negros e a trazida pelos imigrantes, dentre os quais se destacam os italianos.

Anos 90, Porto Alegre, v. 15, n. 27, p. 325-358, jul. 2008 
Parece possível afirmar que o tango foi um "ponto de encontro" entre distintas identidades étnicas. Nas próprias letras das canções que interpretava, Gardel remete a essas distintas etnias. É o caso do tango Giuseppe el zapatero, de Guillermo del Ciancio, gravado em $1^{\circ}$ de dezembro de 1930.

E tique, tuque, taque, se pasa todo el día

Giuseppe el zapatero, alegre remendón

masticando el toscano per far la economia

pues quiere que su hijo estudie de doctor

El hombre en su alegría

no teme al sacrificio

así pasa la vida

contento y bonachón.

¡Ay!, si estuviera, hijo

tu madrecita buena

El recuerdo lo apena

y rueda un lagrimón

Tarareando La Violeta

don Giuseppe está contento

ha dejado la trincheta

el hijo se recebió

Con el dinero juntado

ha puesto chapa en la puerta

el vestíbulo arreglado

consultorio con confort

E tique, tuque, taque, don Giuseppe trabaja

Hace ya una semana el hijo se casó

la novia tiene estancia y dicen que es muy rica

el hijo necessita hacerse posición

E tique, tuque, taque... Ha vuelto don Giuseppe

otra vez todo el día trabaja sin parar

Y dicen los paisanos, vecinos de su tierra

Giuseppe tiene pena y la quiere ocultar 
Perceba-se que Giuseppe é um nome típico italiano, e Gardel fala, nessa canção, de seu quotidiano de trabalho. A figura do descendente de italiano é uma das mais referidas nas canções interpretadas por Gardel. Isso se justifica, em parte, pela própria dimensão da imigração italiana para a Argentina. Conforme Otero (1999, p. 127),

A França ocupou, na Argentina do século XIX, o primeiro lugar como modelo cultural e intelectual das classes dirigentes, o segundo - atrás da Grã-Bretanha - nos investimentos de capital, e o terceiro - depois de italianos e espanhóis - na composição quantitativa do fluxo migratório.

Porém, Gardel referencia, também, uma série de outras identidades étnicas, mesmo as que não foram numericamente significativas, como no foxtrote La bija de japonesita, de Ramón Montes, com letra de Vicente de la Vega e Enrique Pedro Maroni, gravado em 06 de julho de 1928, ou em Caprichosa, fado de Froilán Aguilar, gravado em 19 de setembro de 1930, que remete à etnicidade portuguesa.

Nessas canções, Gardel não faz a identificação desses grupos étnicos como representantes diretos da Argentina. Porém, como pertencentes a segmentos populares em emergência em sua época, parece haver uma indireta representatividade neles. Mesmo não sendo uma síntese plenamente acabada, pois, em suas canções, o espaço do gaucho é definido como separado do espaço do imigrante, essa diversidade de representações encontrada nas canções e na imagem de Gardel apresenta-se como uma tentativa de atingir aos diferentes públicos, talvez uma tentativa de síntese da diversidade que se apresentava por meio do tango.

\section{Carmen Miranda no Brasil}

Enquanto o principal problema étnico em relação à identidade nacional argentina, na época de Gardel, foi pensar a homogeneização entre os imigrantes e os grupos já existentes em 
seu território, o grande problema brasileiro foi pensar a inclusão de sua maioria não-branca na identidade nacional. O Brasil, com largo passado escravista, guardara, em sua cultura, uma forte distinção entre brancos e negros no começo do século XX. Os anos 1930 apresentavam-se, quanto a essa questão, como um marco entre duas formas bem distintas de compreender a etnicidade. Era o momento de assimilação à nacionalidade por parte das identidades populares brasileiras e, dentre estas, concentravam-se os grupos étnicos não-brancos. Enquanto na Argentina dos tempos de Gardel não havia uma associação tão forte entre identidade de elite e identidade branca, até porque a maioria dos segmentos populares dessa nação era de brancos, no Brasil havia uma associação entre brancos e elites e entre não-brancos e segmentos populares.

Como Gardel, Carmen trouxe, em sua trajetória artística, representações de identidades étnicas. No começo de sua carreira, as músicas mostravam que a questão da etnicidade era extremamente forte dentro das idéias que circulavam no imaginário dos grupos para os quais ela cantava. Isso se manifesta em uma freqüente distinção étnica, quando Carmen afirmava quem era branco e quem era negro, atribuindo a cada um desses grupos adjetivos diversos, como em Por amor a este branco, samba de Custódio Mesquita, gravado por Carmen, em 1933, ou O negro no samba, de Ary Barroso, Marques Pôrto e Luiz Peixoto, gravado em 1929.

Samba de nêgo quebra os quadris

Samba de nêgo tem parati

Samba de nêgo, oi, oi, sempre na ponta

Samba de nêgo, meu bem, me deixa tonta

No samba, branco se escangaia

No samba, nêgo bom se espaia

No samba, branco não tem jeito, meu bem

No samba, nêgo nasce feito 
Nesta última canção, percebemos uma relação de identidade do samba com o negro. Essa associação parece-nos, inicialmente, óbvia, pois o samba é um estilo musical com origem negra. Mas como o samba pode afirmar-se como nacional se está associado à identidade étnica dos negros?

Inicialmente, temos de levar em conta o momento da gravação dessa canção. É nas primeiras gravações de Carmen que a forte distinção entre negros e brancos apresenta-se de forma mais clara. Com o tempo, as canções começam, paulatinamente, a não opor negros e brancos, mas a utilizar metáforas alusivas à mestiçagem. Os termos que começam a ser mais freqüentes são "moreno", "gente bronzeada" e "mulato". Por que essa mudança?

O fato de as músicas apontarem expressões que representam a mestiçagem não significa que esta tenha se tornado o ideal da "raça brasileira". Outras versões da identidade nacional, que desqualificavam a mestiçagem, continuaram existindo durante a trajetória de Carmen no Brasil. Contudo, a cantora parece ter adotado, em suas músicas e imagens no decorrer dos anos 1930, cada vez mais representações dessa versão étnica da identidade nacional.

Nesse sentido, é possível afirmar que Carmen dialogava e assumia posições no que se refere às lutas de representações étnicas existentes no imaginário da década de 1930, estabelecendo relações com propostas que se tornaram fundamentais neste período, especialmente as baseadas na obra de Gilberto Freyre. Como fala Ortiz (1985, p. 41),

A passagem do conceito de raça para o de cultura elimina uma série de dificuldades colocadas anteriormente a respeito da herança atávica do mestiço. Ela permite um maior distanciamento entre o biológico e o social, o que possibilita uma análise mais rica da sociedade. Mas a operação que Casa Grande e Senzala realiza vai mais além. Gilberto Freyre transforma a negatividade do mestiço em positividade, o que permite completar definitivamente os contornos de uma identidade que há muito vinha sendo desenhada.

Anos 90, Porto Alegre, v. 15, n. 27, p. 325-358, jul. 2008 
O que nos interessa na obra de Freyre é a influência de seu pensamento nas representações do imaginário da sociedade brasileira. Segundo Fico (1997, p. 34), os anos 1930 foram o período de "gilbertização" do país, ou seja, da absorção de uma explicação da sociedade brasileira a partir da obra Casa Grande e Senzala, que promoveu uma ressignificação dos negros e dos mestiços na cultura nacional. A partir da obra de Gilberto Freyre, a mistura de raças como formadora da identidade nacional ganhou ampla aceitação. A noção de que o Brasil tinha se formado pela miscigenação difundiu-se socialmente e tornou-se senso comum. Como afirma Schwarcz (2000, p. 178), "representação vitoriosa dos anos 30, o mestiço transformou-se em ícone nacional, em um símbolo de nossa identidade cruzada no sangue, sincrética na cultura, isto é, no samba, na capoeira, no candomblé e no futebol."

A obra de Gilberto Freyre ia perfeitamente ao encontro da proposta política de Vargas, assimilando harmoniosamente diversos grupos étnicos à nacionalidade, idealizando uma sociedade sem conflitos e, com certeza, este é um dos motivos de seu pensamento ter se projetado tanto. Como afirma Vianna (1995, p. 73),

O governo pós-Revolução de 30 tornou semi-oficial a política de miscigenação, valorizando inclusive os símbolos nacionais mestiços como o samba [...] As medidas de repressão foram inclusive legais [...] limitando as cotas de imigração [como forma de valorizar o trabalho dos mestiços brasileiros em detrimento dos brancos europeus] e estabelecendo que nenhum estabelecimento de trabalho poderia ter mais do que um terço de empregados estrangeiros.

O pensamento de Gilberto Freyre circulou enormemente e teve influência sobre diversas manifestações artísticas e intelectuais, inclusive sobre as canções interpretadas por Carmen. Evidentemente, havia, no Brasil, vários tipos de miscigenação (o caboclo, o mulato, o cafuzo, o mameluco e todas as nuances entre essas misturas). 
Qual seria eleito como símbolo nacional? Aí também convergem Gilberto Freyre e Carmen Miranda. Em Casa Grande e Senzala, Freyre fala da mistura do branco com o negro, a qual também é destacada por Carmen. Os termos que representam essa miscigenação foram cada vez mais freqüentes nas canções interpretadas pela artista durante a década de 1930. Em 1932, Carmen, abolindo o termo "negro", gravou Mulato de qualidade, samba de André Filho, lançado em agosto do mesmo ano.

Apesar de perceber a importância da obra de Gilberto Freyre nesse contexto, temos de levar em consideração que suas idéias não eram consenso. Paranhos (1999) analisa uma diversidade de discursos sobre o samba envolvendo a questão étnica, como os embates entre José Lins do Rego e Pedro Calmon (o primeiro favorável e o segundo contrário à escolha do samba como símbolo nacional, por motivos de conotação étnica) nos jornais $A$ Noite e O Jornal. Contudo, como frisa o mesmo autor, a figura de Carmen Miranda não deixou de encarnar o "paradigma mestiço". Podemos observar que a versão proposta por Freyre e divulgada por Carmen Miranda tornou-se fundamental na construção do imaginário do Brasil dos anos 1930.

A valorização da miscigenação seria, assim, uma resposta para o conflito étnico brasileiro. Essa valorização pretendia resolver tal conflito unindo todos os brasileiros, tal como havia ocorrido nos países mais adiantados no processo de construção de um imaginário sobre suas nações, unificando, no imaginário social, a identidade étnica que compõe seu povo, para diferenciá-lo de outras nacionalidades. Essas teorias possibilitaram que alguns falassem em uma "raça brasileira", contrariando o passado escravista, que fazia uma clara distinção entre as raças presentes no Brasil. Em Eu gosto da minha terra, samba de Randoval Montenegro, gravado em 1930, Carmen canta:

Deste Brasil tão famoso eu filha sou, vivo feliz Tenho orgulho da raça, da gente pura do meu país 
Mesmo com a presença marcante, no imaginário da época, do triângulo das três raças, estas foram unificadas nessa canção. Falava-se não em diferentes raças, mas em uma raça brasileira formada após todo o processo de miscigenação. A noção de uma "raça brasileira" foi, também, mencionada por Vargas, em 1938, quando declarou que:

um país não é apenas uma aglomeração de indivíduos em território, mas é, principalmente, uma unidade de raça, uma unidade de língua, uma unidade de pensamento. Para se atingir este ideal supremo é necessário, por conseguinte, que todos caminhem juntos em uma prodigiosa ascensão (VARGAS, apud CAPELATO, 1998, p. 145).

Na canção Quem condena a batucada, Carmen canta:

Quem condena a batucada dessa gente bronzeada não é brasileiro

Nessa estrofe, Carmen apresenta uma proposta de síntese étnica do Brasil. O termo "bronzeado" poderia servir tanto para o negro quanto para o branco que, ao sol dos trópicos, "pegou uma cor" quanto para todos os mestiços do Brasil. A batucada e o samba, assim, poderiam deixar de ser representantes dos negros para representar toda a nação mestiça. Carmen, por meio desses versos, parecia estar dando uma resposta aos críticos dessa versão da identidade nacional.

A expressão "bronzeado" também poderia servir ao pensamento de Gilberto Freyre, no sentido de dar prioridade aos elementos brancos latinos, preferencialmente portugueses, como Carmen, na construção da "raça brasileira".

Além das letras das músicas de Carmen, a sua própria figura continha essa mistura étnica que representava a nação. Aí temos mais um elemento que lhe dá legitimidade como representante do Brasil. Como afirma Vianna (1995, p. 130), 
Carmen, que era portuguesa de nascimento e nunca conseguiu obter um passaporte brasileiro, "inventou" [junto a vários artistas, inclusive Dorival Caymmi] uma imagem do Brasil para ser vendida no exterior. Essa imagem, com suas bananas e balangandãs, surgiu no momento em que o "paradigma mestiço", divulgado principalmente por Gilberto Freyre, como já vimos, tornava-se hegemônico no debate sobre a identidade brasileira.

Branca européia, Carmen Miranda não via nenhuma contradição em se vestir de baiana (usando a roupa "típica" das negras da Bahia) ou em cantar ou dançar o samba (música de origem negro-africana).

Dessa forma, ela apresentou, também em termos de etnicidade, uma síntese para representar o Brasil. Servia aos padrões estéticos de beleza das elites brasileiras e, ao mesmo tempo, assimilava elementos que representavam a miscigenação.

Fazendo uma leitura da imagem de baiana criada por Carmen e apresentada, pela primeira vez, no filme Banana da Terra, de 1939, podemos afirmar que as alterações feitas por ela não respondiam apenas a excentricidades suas, mas tinham a ver com a própria brasilidade que ela queria transmitir em suas roupas. Com uma natureza tão pujantemente colorida, não se poderia representar o Brasil com vestes brancas, como as utilizadas pelas baianas originais. $\mathrm{O}$ colorido, associado às nossas belezas naturais, ao Carnaval e a todas as nuances da diversidade étnica da nação, representava muito melhor o Brasil do que o branco. Logo, podemos afirmar que Carmen, ao alterar esse elemento da imagem da baiana, a "abrasileirou". O mesmo ocorre com as duas cestinhas de frutas que Carmen colocou na cabeça, associadas às riquezas naturais do Brasil.

Também Gardel servia aos padrões estéticos de beleza das elites argentinas, além de ter, em sua imagem, o jeito sofisticado delas. Em contrapartida, igualmente assimilava elementos simbólicos associados aos segmentos populares, dentre esses, vários com caráter étnico. Dessa forma, Gardel e Carmen tornaram-se versões 
possíveis da identidade nacional da Argentina e do Brasil, tendo elementos simbólicos que lhes permitiam a aceitação das elites, de diversos segmentos populares e mesmo do Estado, o qual não os percebia como um perigo ou uma ameaça à nação.

As identidades étnicas não deixaram de existir nem na Argentina nem no Brasil. O que Gardel e Carmen apresentavam era uma proposta de síntese, uma proposta de resolução das lutas de representações existentes naquele momento histórico, a qual era caracterizada por uma valorização dos elementos étnicos anteriormente excluídos das identidades nacionais sem, contudo, estabelecer um discurso radicalmente contra os elementos étnicos já inclusos. Essa proposta não se tornou absoluta, mas foi fundamental no imaginário das duas nações no entre-guerras.

Ethnic and national identities representations in Argentina and Brazil by Carlos Gardel and Carmen Miranda

Abstract. In this article, is proposed an analyze about ethnic identities representations in the songs, in the image and in the performance by Carlos Gardel and Carmem Miranda, that were related with national identities by Argentina and Brazil. The hypothesis is that those artists were important in the negotiations trials and argentine and brazilian national identities structure, having in focus the fact that they have been the most famous interpreters in their countries, knowing representation that was got by much people, in a time that nationalism appears between-wars period and mass communication spread. In the songs, in the images and in the performances by both artists, there was also, identities ethnic representations, that were certifies as legitimately nationals. In that sense, we focus character distinct identities - united to ethnic group and nation - establishing an analysis about truth relation by them in this context.

Keywords: Ethnic Identities. National Identities. Carlos Gardel. Carmem Miranda. 


\section{Alessander Kerber}

\section{Notas}

${ }^{1}$ Em minha tese de doutorado, defendida na Universidade Federal do Rio Grande do Sul, intitulada "Representações das identidades nacionais argentina e brasileira nas canções interpretadas por Carlos Gardel e Carmen Miranda (1917-1940)" (KERBER, 2007), analiso essas representações das identidades nacionais presentes nas músicas, na imagem e na performance dos artistas. Neste artigo, proponho analisar a relação construída entre a identidade nacional e as identidades étnicas, em ambos os países, a partir do mesmo corpus documental, em uma perspectiva comparada.

${ }^{2}$ Cabe, nos casos argentino e brasileiro, a divisão proposta por Hroch para os movimentos nacionalistas (cf. HOBSBAWM, 1991, p. 21). As décadas de 1910 a 1930, na Argentina, e, especialmente a de 1930, no Brasil, seriam, justamente, o período de transição entre as fases $\mathrm{B}$ e $\mathrm{C}$, em que há a massificação do nacionalismo. ${ }^{3}$ A carreira de Gardel já se desenvolvera desde muito antes. Desde 1911, Gardel apresentava-se em dupla com o cantor José Razzano. Contudo, o ano de 1917 foi um marco fundamental em sua carreira. A parceria com Razzano aos poucos se desfez e Gardel passou a triunfar absoluto no cenário musical argentino desde então. ${ }^{4}$ Com a exceção significativa de Noel Rosa, que, não se sabe exatamente porque, não gostava da figura de Carmen. Também a principal intérprete de Noel, Aracy de Almeida, manteve, durante boa parte dos anos de 1930, uma relação de desavença com Carmen.

${ }^{5}$ Necessário mencionar que Carmen e Gardel atuaram essencialmente em filmes musicais, cujo momento fundamental se dava exatamente nos momentos em que interpretavam uma canção. Carmen, até o final da década de 1930, atuou nos filmes A voz do Carnaval (1933), dirigido por Adhemar Gonzaga e Humberto Mauro (Cinédia); Alô, alô, Brasil (1935), dirigido por Wallace Downey, João de Barro e Alberto Ribeiro (Waldow-Cinédia); Estudantes (1935), dirigido por Wallace Downey (Waldow-Cinédia); Alô, alô, Carnaval (1936), dirigido por Adhemar Gonzaga (Waldow-Cinédia); Banana da terra (1939), dirigido por Wallace Downey (Sonofilmes); Down Argentine Way (1940), dirigido por Irving Cummings (Fox). Não restaram cópias dos filmes mais antigos que contaram com sua participação.

Gardel atuou, em 1930, em dez curtas, nos quais sempre canta um número de seu repertório: Añoranzas; Cancero; Enfundá la mandolina; Mano a mano; El carretero; Padrino pelado; Rosa de otoño; Tengo miedo; Viejo smoking; Yira, Yira. Também atuou em Luces de Buenos Aires (1931), dirigido por Adelqui Millar (Paramount); Esperame (1932), dirigido por Luis Gasnier (Paramount); La casa es seria (1932), dirigido por Jaquelux (Paramount); Melodía de arrabal (1933), dirigido por Luis Gasnier (Paramount); Cuesta Abajo (1934), direção de Luis Gasnier (Paramount); El tango en Broadway (1934), dirigido por Luis Gasnier (Paramount); The big broadcast of 1935 (1935),

Anos 90, Porto Alegre, v. 15, n. 27, p. 325-358, jul. 2008 
dirigido por Norman Taurog e Theodore Reed (Paramount); El día que me quieras (1935), dirigido por John Reinhardt (Paramount); Tango Bar (1935), dirigido por John Reinhardt (Paramount).

${ }^{6}$ No caso de Carlos Gardel, o dia 14 de outubro de 1917 marca o início de sua carreira solo e, também, o que passou a ser considerado como o início da "Guardia Nueva”, com sua apresentação do tango Mi noche triste, no Teatro Empire. No ano de 1935, Gardel tem uma morte trágica, pondo fim à sua carreira e tornando-o, talvez, o maior mito da história argentina. No caso de Carmen Miranda, o marco inicial são os anos de 1929, quando inicia suas gravações discográficas, e de 1930, quando houve seu grande sucesso, com Taí. No ano de 1939, ela embarca para os Estados Unidos, fazendo um ano de carreira nesse país, retornando para o Brasil em 1940. ${ }^{7}$ Dentre esses autores, destacam-se os trabalhos de Capelato (1998), Ferreira (1989), Gomes (1999) e Paranhos (1999).

${ }^{8}$ A partir de exaustivo trabalho com diversas fontes, Collier intitula o primeiro capítulo de seu livro sobre Gardel de "El niño de Toulouse". Gardel nasceu Charles Romuald Gardes, em 1890, na França, filho de Berthe Gardes e de pai desconhecido. Quando perguntado, porém, sobre sua real nacionalidade por algum jornalista, Gardel respondia: "Mi patria es el tango" ou "Soy ciudadano de la calle Corrientes" (COLLIER, 1988, p. 91).

Carmen Miranda também não havia nascido no Brasil, mas em Portugal. Na década de 1930, quando surgiu como grande estrela, a origem portuguesa de Carmen foi mantida em segredo. Seu comportamento e sua fala, empregando constantemente gírias das camadas populares do Rio de Janeiro, faziam com que fosse difícil alguém imaginar sua origem imigrante. Quando "vazou" a informação de que era portuguesa, um jornalista do jornal O País perguntou se ela nascera no Rio. Ela respondeu que "era filha de Portugal, embora seu coração fosse brasileiro” (GIL-MONTERO, 1989, p. 39).

\section{Referências bibliográficas}

AGUINIS, Marcos. O atroz encanto de ser argentino. São Paulo: Bei Comunicação, 2002.

ANDERSON, Benedict. Nação e consciência nacional. São Paulo: Ática, 1989. ARCHETTI, Eduardo P. O "gaucho", o tango, primitivismo e poder na formação da identidade nacional argentina. Mana, Rio de Janeiro, v. 9, n. 1, p. 9-29, 2003.

BACKZO, B. A imaginação social. In: ROMANO, Ruggiero (org.). Enciclopédia Eunaudi. v. 5. Lisboa: Imprensa Nacional, 1985. p. 296-331.

BARTH, Fredrik. Grupos étnicos e suas fronteiras. In: POUTIGNAT, Philippe; STREIFF-FENART, Jocelyne (orgs.). Teorias da etnicidade. São Paulo: Fundação Ed. da UNESP, 1998. p. 187-227.

Anos 90, Porto Alegre, v. 15, n. 27, p. 325-358, jul. 2008 


\section{Alessander Kerber}

BLOCH, Marc. Pour une histoire compareé des societés européennes. In: Melanges historiques. Paris: Sevpen, 1963. p. 16-40.

CAPELATO, Maria Helena Rolim. Multidões em cena: propaganda política no varguismo e no peronismo. Campinas: Papirus, 1998.

CARDOSO JUNIOR, Abel. Carmen Miranda: a cantora do Brasil. São Paulo: edição particular do autor, 1978.

CARRETERO, Andrés. Tango: testigo social. Buenos Aires: Pena Lillo/Ediciones Continente, 1999.

CHARTIER, Roger. A bistória cultural: entre práticas e representações. Lisboa: Bertrand Brasil/Difel, 1990.

- À beira da falésia: a história entre incertezas e inquietude. Porto Alegre: Editora da UFRGS, 2002.

COLLIER, Simon. Carlos Gardel: su vida, su música, su época. Buenos Aires: Editorial Sudamericana, 1988.

DART, Thurston. Interpretaşão da música. São Paulo: Martins Fontes, 1990.

DEVOTO, Fernando J. Imigrações européias e identidade nacional nas imagens das elites argentinas (1850-1914). In: FAUSTO, Boris (org.). Fazer a América: a imigração em massa para a América Latina. São Paulo: EDUSP, 1999. p. 33-60.

FAUSTO, Boris; DEVOTO, Fernando. Brasil e Argentina: um ensaio de história comparada (1850-2002). São Paulo: Ed. 34, 2004.

FERREIRA, Jorge Luiz. Os trabalhadores do Brasil: a cultura popular no primeiro governo Vargas (1930-1945). Niterói, 1989. 216 f. Dissertação (Mestrado em História) Universidade Federal Fluminense.

FICO, Carlos. Reiventando o otimismo: ditadura, propaganda e imaginário social no Brasil. Rio de Janeiro: Ed. Fundação Getúlio Vargas, 1997.

GARCIA, Tânia Costa. A canção popular e as representações do nacional no Brasil dos anos 30: a trajetória artística de Carmen Miranda. História: questões e debates, Curitiba, ano 16, n. 31, p. 67-94, 1999.

GIL-MONTERO, Martha. Carmen Miranda: a pequena notável. Rio de Janeiro: Record, 1989.

GOMES, Ângela de Castro. Ideologia e trabalho no Estado Novo. In: PANDOLFI, Dulce (org.). Repensando o Estado Novo. Rio de Janeiro: FGV, 1999. p. 53-71.

HAUSSEN, Doris Fagundes. Rádio e política: tempos de Vargas e Perón. Porto Alegre: EDIPUCRS, 1997.

HOBSBAWM, Eric. Nacões e nacionalismo desde 1780. Rio de Janeiro: Paz e Terra, 1990. KERBER, Alessander. Representacōes das identidades nacionais argentina e brasileira nas cançoes interpretadas por Carlos Gardel e Carmen Miranda (1917-1940). Porto Alegre, 2007. 315 f. Tese (Doutorado em História) - Universidade Federal do Rio Grande do Sul. MARTINEZ, Roberto L.; ETCHEGARAY, Natalio P.; MOLINARI, Alejandro. De la vigüela al fueye: las expresiones culturales argentinas que conducen al tango. Buenos Aires: Corregidor, 2000.

Anos 90, Porto Alegre, v. 15, n. 27, p. 325-358, jul. 2008 
NAPOLITANO, Marcos. Canção e trabalho no Brasil. In: III SIMPÓSIO NACIONAL DE HISTÓRIA CULTURAL. Florianópolis: UFSC, 2006.

ORTIZ, Renato. Cultura brasileira e identidade nacional. São Paulo: Brasiliense, 1985. OSTUNI, Ricardo. Tango: voz cortada de organito. Buenos Aires: Lumiere, 2005.

OTERO, Hernán. A imigração francesa na Argentina: uma história aberta. In: FAUSTO, Boris (org.). Fazer a América: a imigração em massa para a América Latina. São Paulo: EDUSP, 1999. p. 127-151.

PARANHOS, Adalberto. O Brasil dá samba? Os sambistas e a invenção do samba como "coisa nossa". IN: TORRES, Rodrigo (org.) Música popular en America Latina. Santiago: Fondart, 1999. p. 193-232.

PELUSO, Hamlet; VISCONTI, Eduardo. Carlos Gardely la prensa mundial. Buenos Aires: Corrigidor, 1998.

PESAVENTO, Sandra Jatahy. Trabalhadores e máquinas: representação do progresso (Brasil: 1880-1920). Anos 90, Porto Alegre, n. 2, p. 165-182, 1994.

PRIETO, Adolfo. El discurso criollista en la formación de la Argentina moderna. Buenos Aires: Sudamericana, 1988.

ROJO, Raúl Enrique. Hombres mirando al sur. En torno de la identidad de argentinos y brasileños. Horizontes Antropológicos, Porto Alegre, ano 2, n. 4, p. 121-126, jan./jun. 1996.

SCHWARCZ, Lilia Moritz. Nem preto nem branco, muito pelo contrário: cor e raça na intimidade. IN: SCHWARCZ, Lilia Moritz (org.) História da vida privada no Brasil 4: contrastes da intimidade contemporânea. São Paulo: Companhia das Letras, 2000. p. 173-244.

THIESSE, Anne-Marie. Ficções criadoras: as identidades nacionais. Anos 90, Porto Alegre, n. 15, p. 07-23, 2001/2002.

VARELA, Sergio. Tangos que cantó Gardel. Buenos Aires: DISTAL, 1998.

VELLOSO, Mônica Pimenta. As tias baianas tomam conta do pedaço - espaço e identidade cultural no Rio de Janeiro. Estudos Históricos, Rio de Janeiro, v. 3, n. 6, p. 207-228, 1990.

VIANNA, Hermano. O mistério do samba. Rio de Janeiro: Jorge Zahar/Ed. UFRJ, 1995.

Recebido em 22/08/2008. Aprovado em 15/12/2008. 